\title{
Competitiveness and Sustainability in Tourism Industry: The Albergo Diffuso Case Study
}

\author{
Marco Valeri ${ }^{1} \&$ Paola Paoloni ${ }^{2}$ \\ ${ }^{1}$ Research Fellow of Organizational Behaviour, Faculty of Economics - Niccolò Cusano University Rome, Italy \\ ${ }^{2}$ Full Professor of General Management, Faculty of Economics, Niccolò Cusano University -Rome, Italy \\ Correspondence: Marco Valeri, Research Fellow of Organizational Behaviour, Faculty of Economics - Niccolò \\ Cusano University Rome, Don Gnocchi Street, 00166 Rome, Italy. E-mail: marco.valeri@unicusano.it
}

Received: October 2, 2017

doi:10.5539/ijbm.v12n12p107
Accepted: October 23, $2017 \quad$ Online Published: November 20, 2017

URL: https://doi.org/10.5539/ijbm.v12n12p107

\begin{abstract}
The objective of the analysis developed in this paper is to verify whether the sustainability of the hotel ospitality model contributes to the competitiveness of tourist destinations. The research question is: does the model of "albergo diffuso" satisfy the requirement for a social, economic and environmental sustainability? The research method adopted consisted in a survey with the submission of a questionnaire to a number of alberghi diffusi operating worldwide, that is 130 units of analysis. The submission period went from October to December 2016. Through the questionnaire submitted to the interviewees it has been possible to analyze the motivation for the business start-up as well as the characteristics of the entrepreneur, the managerial systems and the governance style. The results will be analyzed through the application of the Weaver model $(2014 ; 2017)$ which is considered essential to evaluate the contribution of the albergo diffuso to tourism sustainability. The implementation of the Weaver matrix to evaluate the contribution of the albergo diffuso to the sustainability of a tourist destination is the original element of the paper. The paper discusses the implications of sustainability with particular regards to the "albergo diffuso". Therefore, it would be suitable to expand the analysis to additional models of tourist hospitality present in the international tourism scenario.
\end{abstract}

Keywords: Entrepreneurship, sustainability, destination management and governance, rural tourism, competitive advantage

\section{Introduction}

Tourists are becoming more sensitive to their leisure time experiences and are more interested in authenticity and having closer relations with the local population.

If we are to understand and control the dynamics emerging in the tourist industry, we need to analyse the problems of governance and management in the tourist destination itself. It is therefore crucial that tourist businesses are aware of and can evaluate the external environment, and provide professional and responsible answers (Sainaghi, 2006; Baggio et al., 2010; Bramwell \& Lane, 2011). This can be a possible source of creativity for more sustainable development (Choi \& Sirakaya, 2006; Jamal \& Stronza, 2009; Hall, 2010). Therefore tourism businesses must pay attention to the needs expressed by tourists visiting their competitors' tourist destinations in order to devise consistent strategies (Nahapiet \& Ghoshal, 1998; Buhalis, 2000; Dwyer et al., 2009).

When the competitiveness of tourism enterprises is measured on their ability to give unique experiences to tourists, it is the responsibility of the governance and management of these enterprises to focus on actions that will create value for tourists, with the purpose of: a) improving the quality of accommodation and tourism services; b) enhancing the quality of tourism based on intangible resources, integrating it with social, economic and environmental aspects of the territory; c) promoting and enhancing the local intangible cultural heritage.

This requires sustainable organizational models, indispensable for the creation of innovative tourism services, which will be able to engage and remunerate all the stakeholders. Such processes must be able to enhance and consolidate the system of relationships between the different stakeholders involved. It presupposes cooperation between tourism enterprises and tourism service providers in a co-evolution project that will require innovative processes, some clear and transparent relationships with all the parties involved and a proactive and reactive role 
played by tourism enterprises alongside the host communities. When a tourism firm aspires to be sustainable it should not stay isolated from its background; it should create instead a wider network with other firms and with all the stakeholders it has (Buckley, 2012; Volgger \& Pechlaner, 2015).

The need to satisfy their very different needs in a sustainable way has led to the development and success of specific business formulas - in particular, the phenomenon of the albergo diffuso and of the rural tourism business, the so-called agritourism .

These tourist hospitality systems are similar and offer an authentic and original way of distribution of tourist services to an increasingly demanding audience of customers. The two business models share a significant attention towards the territory and its centrality in the management and in strategic processes. They both enhance the connection between the territory with its typical products and tourists, however they differ in terms of structure, organization and management.

Agritourism business is the result of a strategic path of growth of small agrarian enterprises in the tourist sector, representing a good example of how to promote local agricultural production.

The albergo diffuso is an original and Italian model of hospitality (Monge et al., 2015). Although still limited in number, the structures are being widely developed and are becoming appreciated for their originality also at an international level (Confalonieri, 2011). An albergo diffuso is a hotel accommodation situated in the centre of a small medieval town or village where there is a lively sense of community; the hotel is not in a single building, but consists of two or more separate nearby lodgings that provide guests with normal hotel services. It has to conform to the following requisites: 1) it is run directly by an individual owner as a private business; 2) hotel services and reception area are provided to all guests staying in the various 'scattered' lodgings; 3) rooms are decorated in a consistently authentic and local style; 4) the hotel is professionally managed in order to offer an authentic experience to the guests, and is part of a genuine community. This type of hospitality business also aims at conserving existing buildings which otherwise might end up abandoned or derelict. The rooms and reception are located in the center of an existing inhabited community, while food and drink are provided in a separate locale common to all the lodgings.

According to the literature concerning this subject, it would be useful to ask the following research question: does the model of "albergo diffuso" satisfy the requirement for a social, economic and environmental sustainability?

The paper includes three sections: on a review of tourism sustainability literature, with particular attention paid to governance issues and the management of tourist destinations, seen as a vehicle for the creation of value and for sustainable development; the second part will present the albergo diffuso organizational model. The third part will be devoted to the qualitative survey that will allow the evaluation of how the model of albergo diffuso may contribute to the sustainability of tourist destinations.

\section{The Literature Review}

The connection linking tourist destinations with the environment shows how sustainability is pertinent to the competitiveness of destinations (Buhalis, 2000; Ruhanen et al., 2010). The positive relationship between sustainability and competitiveness, that actually guarantees a favorable outcome for both subjects, is built on the conviction that companies that aim at achieving the enhancement of environmental, economic and social aspects may have significant advantages from such activity (Valeri, 2015)

Currently tourist destinations find themselves more and more involved in a tough competition at global level. This forces them to think and act more like businesses than they ever did. Over the past twenty years, uncertainness and incongruities have often affected the growth of the tourism sector. As for its level of sustainability and community outreach, the development of tourist destinations has been the content of a debate involving quite a large spectrum of disciplines.

Tourists and tourism services are no longer the only elements involved in the tourist business: hence, it is necessary to have the capacity to manage the interactions among all stakeholders that somehow contribute to the tourism sector's offer. From this point of view, the way in which single tourist companies are able to keep up with their competitors, both on national and international scale, influence the competitiveness and sustainability of tourist destinations (Hall, 2010). This suggests that a tourist destination, that is keen to work in a given territory, needs to set its own operating limits and - most importantly - create a form of governing body, that can be both private and public (Coles et al., 2013), and that is able to develop a strategic plan designed to improve the quality not only of the companies, but also of the local tourist attractions (Ritchie \& Rouch, 2000).

The tourist destination is considered as a method of government and management of the relationships between 
all the actors involved in the tourist business, intended to consolidate and increase its competitiveness, both domestic and international. What makes a tourist destination competitive is its capacity to offer an original portfolio of tourist products and enhance the worth of the accommodation. Operating in such an ambitious and rival context, tourist businesses may become more competitive by pursuing sustainability. Competitiveness means that the aim of government and management of tourist destinations is to satisfy the ever more demanding requests of the tourist.

The management literature of the tourist industry tells how a tourist destination can be analyzed in different ways according to a number of distinct features (such as tourist demand- side approach and tourist supply - side approach). At the same time, it also focuses on the issues and related systems of managing a tourist destination (Fu Chen \& DungChun, 2007). The designation of a governance's authority is of primary relevance to improve the level of competitiveness of a tourist destination. Choices and activities of the governance identify their priority targets in the consolidation and subsequent improvement of the destination, and in the definition of precise development purposes shared by all actors involved in the tourism industry.

Creating a governing authority for a tourist destination can be a very complicated process that needs to take into consideration the distinguishing characteristics of the area. More precisely, a strategic coordinating authority cannot be a single individual, but rather a more articulated body.

Such executive body must be able to recognize and exploit the features defining the cultural identity of a destination, whether they are concrete or not, and measure them against those of rival destinations, both locally and internationally. Naturally, this is possible only on the conviction that the executive bodies of each company or destination agree- either directly or indirectly - on their respective decisions and above all that such decisions are aimed at improving the tourist appeal and the competitive features of the destination.

Besides shareholders who are directly involved in the governing process, also managers, providers, and other individuals with an interest in that specific destination are somehow committed to it. These latter represent important stakeholders, such as companies or bodies, who play a key role on the territory. Different subjects produce different effects: providers or tourist service industry may influence the true utilization of the destination; whilst public organizations or citizens' associations may attract masses attention (Gossling et al., 2009).

To develop a mixed tourist portfolio within a tourist destination, it is essential to create a governing authority, however this is not sufficient. A support system comprising a meta-management unit should be established in order to lead local tourist companies towards a strategic and coherent direction. This should not to be considered as a replacement of the governing body, but a concrete aid to promote strategic decisions to be shared and accepted by parties interacting in the destination, whether we are talking about public bodies or private persons.

Governing a tourist destination is just as complex as managing a tourist company. Organizing the decision-making process and allocating resource-controlling powers are the most challenging objectives. Examples refer to destinations organized along with strict hierarchy and precise managerial and procedural guidelines, and also to destinations of corporate or community model (Bieger, 1998; Flagesta \& Hope, 2001). Such great differences in organizing the tourist offer portfolio means different governance criticalities and challenges.

In corporate-model destinations, such as tourist villages, theme parks, resorts, etc., it is a company that after examining the available local tourist attractions, outlines the tourist offer portfolio and that, either in a direct or in an undirected form, holds the complete control of the destination thanks to a contractual agreement. In this circumstance, it is possible to consider the tourist destination as an authentic business and the issues addressed by the governance are quite similar to those of other tourist organizations.

Unlikely the corporate-model, the community-model tourist destinations offer a different type of attractions, that is to say natural and handcrafted products. These types of attractions are not offered by a company but by the local industry. The different local resources belong to various single and independent companies, with individual and specific targets as concerns investment policies and profit generation, thus making the governance more entangled. In this case, competitiveness of the tourist sector strongly depends on local institutions, that manage both natural and handcrafted attractions, and that can endowers the tourist offer when it comes to sustainability (Valeri et al., 2016).

In order to monitor fulfilment and evaluate progress towards tourism sustainability, a number of procedures have been recommended (Schianetz et al., 2007) since the late ' 80 of last century, when Brundtland Commission introduced the theory of sustainable development (World Commission on Environment and Development, 1987). Most of the debate is focused on life cycle evaluation, environmental management standards, sustainability 
indicators (Choi \& Sirakaya, 2006; Twining-Ward \& Butler, 2002), impact assessment (Warnken \& Buckley, 1998), multi-criteria analysis (Zografos \& Oglethorpe, 2004) and interaction between sustainable growth and competitiveness (Chien-Min et. al., 2011). Nevertheless, such evaluation methods of practices related to tourism sustainability should also take into consideration the dynamic character of these two variables, i.e. tourism and sustainability, and the connections among the different stakeholders who have specific expertise and different or opposite opinions (Jamal \& Stronza, 2009; Saarinen, 2006).

We can define sustainable development as a "development that meets the needs of the present without compromising the ability of future generations to meet their own needs."

This concept, presented for the first time in 1987 by the Brundtland Report, is today largely accepted and is suitable for a large variety of economic and social contexts, at both emerging and developing stage. In addition, it comprises three primary features of development, i.e. economic, social and environmental (Buckley, 2012). A sustainable growth has to consider and connect these three key principles or better yet three goals: economic effectiveness, social effectiveness and environmental effectiveness.

We talk about economic effectiveness when it refers to the promotion of the business institutional mission and objectives, bearing in mind that real progress needs investments in innovation in order to increase competitiveness, achieve satisfactory profit and, at the same time, create wealth and comfort for the local population. Therefore, companies must always operate with the utmost effectiveness so as to keep their edge in the long period. We talk about social effectiveness when it refers to the attention for people's needs, either individual or group, and to the respect of their rights and opportunities in a fair and equitable way. In other words, a company should keep fair relationships with workers and other stakeholders, in particular, it should try to meet the needs and expectations of local population. We talk of environmental effectiveness when it refers to the attention for the ecosystem and its natural resources, in particular for those that are not unlimited or are strictly necessary for human beings existence. Earth natural legacy deserves great respect as well as the exploitation of its resource that should be carried out with the utmost rationality, avoiding harm to the environment and to the nature's harmony (Schianetz et al., 2007).

From the description of the above principles, we can understand how essential is to be engaged in respecting the territory and having care for the harmony of its social aspects and ecosystems, more precisely for its environment, economy and culture. Likewise, it is fundamental that such attitude is governed with effectiveness and efficiency, and with the constant involvement of the local population in any decision.

If tourist companies and tourist destinations act as real and dynamic partners of the local communities, trying to bring advantages without doing any harm to the territory, they can easily survive. Tourism should not neglect the key role of innovation as well (Saarinen, 2006). This implies that a fundamental part is played by the commitment in social responsibility and the related possible competitive edge than can derives; we talk about sustainable tourism when it acts fairly and hectically. In Italy, the leading edge of business management is more and more oriented towards a governing style that pays particular attention to ethical values and to the respect of future generations' needs, rather than to economic or material returns.

Innovative and sustainable tourism projects cannot ignore the creation of organizational environments which allow the sharing of new knowledge between enterprises and external environments. Governance and management of tourism firms have a responsibility to create an environment which is conducive to the development of new cost-effective and socially acceptable tourism services, protecting the local resources (Schianetz et al., 2007).

\section{The Weaver Model}

In accordance with Weaver's theory $(2000 ; 2010)$, the ability of a tourist destination to face competitors is strictly connected with the degree of sustainability of its development in tourist offering. A satisfactory level of sustainability is possible only when two specific conditions are well balanced: tourist intensity (the percentage of tourists and dwellers, the quantity of workers, the number of accommodation and the average period of stays) and regulation (laws on tourism, on environment exploitation and its protection, respect for dwellers' needs and protective measures for the local cultural legacy). In the evaluation of the competitiveness's degree of a tourist destination, these two prerequisites have to be thoroughly achieved and considered as elements of priority. The relationship between these two elements gives origin to a four-matrix quadrant; the four quadrants show the various tiers of sustainable development of a tourist destination:

a) Unsustainable Mass Tourism (UMT), a tourism tier characterized by a high level of tourist intensity and a low degree of regulation. Here, economic advantages predominate and the attitude towards the issues of environment 
and social protection is diffident. The territory is heavily exploited by tourist infrastructures and resorts, with very low respect for a possible negative impact;

b) Sustainable Mass Tourism (SMT), a tourism with a high degree of both intensity and regulation. There's a satisfactory balance between the need of the area to grow economically thanks to tourism and the awareness of the territory's limits in terms of environmental exploitation and its possible negative effects on local communities;

c) Deliberate Alternative Tourism (DAT), this is the tier in which territory is not completely explored. The number of tourists is still limited as well as the related laws and regulations. The development of tourism goes hand-in-hand with the willingness of preserving natural resources and respecting the culture and the socio-economic status of the specific geographic area.

d) Circumstantial Alternative Tourism (CAT), refers to the first stage of exploration of the tourist destination. Tourist intensity and regulation are particularly low. There are no precise plans for future development and no processes to promote the territory attractions or support the growth of tourist services.

Tourist intensity and regulation are the key elements of the Weaver matrix and can be considered as a sort of metric useful to evaluate the sustainability of different models of tourism growth, and to control and manage their long terms evolution. Tourist intensity is determined by the flow of tourists and can be used to classify the different models of niche tourism (CAT and DAT) and of mass tourism (SMT and UMT) (Weaver, 2014; 2017). Niche destinations generally experience lower tourist flows, whilst mass destinations receive legions of tourists, hence a very high tourist intensity. On the other hand, the regulation element of tourist flows and of encouragements to enhance quality can be used to identify the sustainability (DAT, SMT) or non-sustainability (CAT, UMT) of both niche and mass destinations. The first (DAT) are sustainable whether they have the ability of capturing shares of sustainable tourist market and of being committed to protecting local natural resources and the culture of local communities. When talking about sustainable mass destinations (SMT), the degree of regulation is high and this means that it is possible to manage big flows of tourists without overtaking the capacity of the environment and of local culture. If regulation is not appropriate, mass destinations may go beyond the limits of the capacity of the territory and risk to develop into non-sustainable (UMT). On the contrary, the reduced demand that niche destinations (CAT) can attract makes them unable to develop economically; actually, they can overcome the stage of exploration only if they introduce a suitable regulation. However the theory expressed by Weaver states that mass tourism and niche tourism models not only do they not conflict but they may even run together towards patterns of sustainable tourism, if they adopt a proper managerial organization.

The limits of intensity and regulation, and how they are able or unable to influence the above conditions, are strictly connected with the low level of accountability of the subjects in charge: for some aspects the tourist companies, for some others the territory. The way in which these two variables interface with each other is relevant (Weaver, 2012). The regulation level should rise actively so as to achieve a sustainable growth for the tourist destination, no matter the degree of tourist intensity. If the regulation is more focused on environment and socio-economic issues, the destination will benefit from this scheme and will become more competitive on the market, no matter how much intense is the tourist flow. On this assumption, Weaver designed a matrix that help analyzing the sustainability of the model of albergo diffuso. The matrix consists of a methodological framework and allows to identify the competitive position of a tourist destination and assesses its probable trails of growth in relation to the variables of intensity and regulation.

\section{The Research Methodology}

The research method adopted is that of case study research (Yin, 2009). The economic field studied is the tourist segment of the albergo diffuso that, despite its restricted number, i.e. 130 units of analysis all based in Italy, represents a growing tourist phenomenon. The research was carried out by submitting a questionnaire to the owners of the subject facilities, which amounted to 130 units of analysis. The questionnaire was sent via e-mail and the interviewees' contact details were found on the internet sites of tourist businesses.

The questionnaire was distributed from October to December 2016. In order to ensure a higher level of reliability and credibility of the empirical survey, the interviewed people were not informed that data would be contextualized within the Weaver matrix. Therefore, we can assume that the given answers were not influenced for the final purpose of the analysis. The questionnaire was structured in an array of open questions directed towards analyzing the distinctive factors of an albergo diffuso that we can summarize as follows: 1) personal features of the entrepreneur, 2) organizational aspects and style of management and 3) business start-up motivations. 
In this research the same determinants are investigated by analyzing the following main points: 1) the geographical location, 2) the number of housing units, 3) the historical - cultural identity and architecture of the housing units in each albergo diffuso, 4) the organizational aspects and style of leadership, 5) the initial motivation of the business.

The results will be evaluated by applying the Weaver model $(2014 ; 2017)$, considered essential to calculate the contribution of the albergo diffuso to tourism sustainability. The Weaver matrix is essential for the measurement of a tourist destination's ability of competing with rivals and for the evaluation of possible future trails in relation to two significant elements: a) tourist intensity (the percentage of tourists and dwellers, the quantity of workers, the number of accommodation and the average period of stays) and b) regulation (laws on tourism, on environment exploitation and its protection, respect for dwellers' needs and protective measures for the local cultural legacy). The relationship between these two variables gives origin to a four-matrix quadrant; the four quadrants show four possible tiers of growth: 1): Unsustainable Mass Tourism (UMT); 2) Sustainable Mass Tourism (SMT); 3) Deliberate Alternative Tourism (DAT); 4) Circumstantial Alternative Tourism (CAT).

Therefore, these factors can be observed and revisited in the light of our research question: does the model of "albergo diffuso" satisfy the requirements for a social, economic and environmental sustainability?

\section{Results}

The albergo diffuso is an original Italian business model. Because of its peculiar structure, this type of tourist hospitality, seems to be only present in Italy and so far there are no reports of scattered hotels elsewhere in the world (Vallone et al., 2013; Paniccia et al., 2014; Tani \& Papaluca, 2015; Valeri \& Fadlon, 2016; Paniccia \& Leoni, 2017). The idea of 'scattered hospitality' goes back to the 1976 earthquake in Friuli Venezia Giulia, where whole villages of Carnia were converted into tourist facilities. Diffuso means that the enterprise is integrated into the socio-cultural reality of the place. The buildings that house the hotel services and accommodation, as well as their furnishings are all authentic and pre-existing (nothing new is built, only carefully restructured) (Paniccia et. al. 2010; Valeri, 2013). In 2016 there were 130 alberghi diffusi in Italy, classified as follows: a) 68 located in historic towns, b) 27 in historic residences, and c) 35 in old farmhouses (Alberghi Diffusi Italian Association, 2016).

The alberghi have an average number of 18 rooms and 30 beds. The highest concentration is located in Central Italy where there are 48 units, 25 units are located in southern Italy, 23 units on Sicily and Sardinia and 34 units located in Northern Italy. It is remarkable that Sardinia, the first to put the idea into practice, has 6 units of which 5 are historic villages transformed into alberghi diffusi (Fig. 1).

In terms of space, alberghi diffusi are organized horizontally, since the bedrooms consist of single houses in the medieval town centre, restored and restructured in keeping with local architectural traditions.

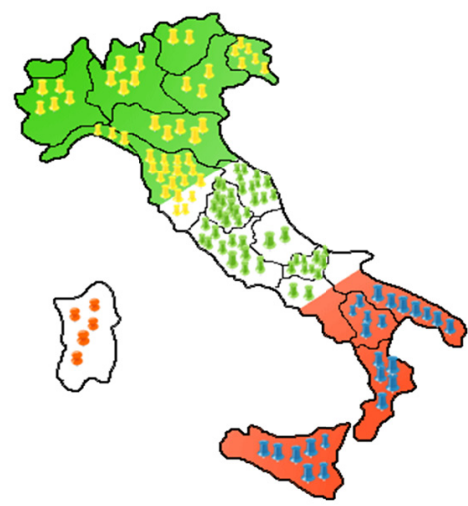

Figure 1. Map of alberghi diffusi in Italy (2016)

Source: our elaboration.

Some hotels are spread through a historic small mountain village or hill-town; sometimes the structure of the hotel extends to cover a large part of the village, becoming an example of an authentic experience in which the village and its inhabitants, the farmers and artisans who live there become part of the experience of hospitality together with the guests. Other hotels are set up in a rural or mountain area which, while not constituting a 
historic village, is, however, a locality rich in local colour; still other hotels also are located in the centre of small or large cities.

From the technical and organizational point of view, a second common feature is that the bedrooms are all located within the pre-existing units. They are of different sizes, independent, and at a distance generally not more than 200/300 meters from the main building, which acts as reception and an information centre.

Unlike in traditional hotels, the restaurant is considered an ancillary service and is usually absent; however, in most of the cases analysed, we found that this activity is given special attention in some alberghi diffusi where there are annexed farms, sometimes of considerable size; the restaurant business then plays an obvious role in the socio-cultural as well as the economic sphere. Similarly, the information service to tourists is often supplied by small libraries, mini-museums, lessons on local cuisine, etc. These services are very different from the more traditional management activities of standard hotels (reception, information, accommodation, catering), as some of the owners of alberghi diffusi said (Avram \& Zarrilli, 2013; De Montis, 2015). During periods of increased tourist influx, some alberghi diffusi offer rented accommodation in houses owned or rented by residents, in addition to the homes owned by the hotel. The different historical, cultural and architectural features of the lodgings that make up the hotels we studied (old houses in a historical village, farms, detached agricultural buildings) and their equally varied dissemination in the area are very important distinctive elements, not only compared to other traditional formulas but also within the hotel segment of the alberghi diffusi business.

Despite the several different interpretations given by tourist operators, the albergo diffuso and agritourism are two types of tourist hospitality with similar features, which have identified an original way of supplying tourist services to an increasingly demanding audience of customers.

The two business models share a significant attention towards the territory and its centrality in the management and strategic processes. They both enhance the connection between the territory with its typical products and tourists, however they differ in terms of structure, organization and management.

Agritourism grew as a transformation of agricultural farms into tourist businesses. They represent a good example of enhancement of a territory with a view to the sustainable tourist development supporting competitiveness of agricultural production.

Agritourism, considered in the strict sense of tourist hospitality inside farms, grew thanks to farmers' initiatives with the aim to integrate their core business, that was becoming less profitable, with tourist activities. Among agritourist activities we can find the following: a) accommodation in buildings or in open areas; $b$ ) meals with food and beverage, mostly produced on the farm or by local farmers: c) sampling of farm products, including wine tasting; d) organization of leisure, cultural, educational and sporting activities, as well as hiking and horse-riding, also outside the agritourism area, thanks to special agreements with local authorities, aiming at promoting the territory and its rural heritage.

To measure rural tourism infrastructure of rural tourism, the metric used is the quantity of bed places that are available in rural accommodation structure. In 2015, nearly $87 \%$ of the total bed places were located in Europe, however the distribution was not balanced throughout the EU Nations. France and Italy together have about $37 \%$ of total European bed places. UK represent $14.8 \%$ and Spain 12.9. The total bed places of these four countries represent nearly two-thirds of the total available in Europe.

Croatia and Czech Republic have the highest rate of bed places in Europe, with $22.6 \%$ and $17.9 \%$ respectively. In Europe, rural areas offer $46.7 \%$ of bed places, towns and suburbs 31.3 and cities the remaining $22.8 \%$. Rural tourist is well developed in Luxemburg, Denmark, Croatia and Austria with bed places share exceeding $70 \%$ out of their national total. Finally, in France $20.1 \%$ of total bed places are in rural regions, in Italy $15.4 \%$ and Germany 9.9\% (WTO, 2015).

\section{Discussion}

The survey was carried out by means of a questionnaire aimed at analyzing the distinctive factors of an albergo diffuso. They can be summarized as follows: 1) entrepreneur's personal characteristics, 2) managerial system and governance style and 3) driver of the business start-up.

Therefore, these factors can be observed and revisited in the light of our research question: does the model of "albergo diffuso" satisfy the requirement for a social, economic and environmental sustainability?

By analyzing the responses received from the owners of the alberghi diffusi, we learnt that these two hotels were the most typical examples of the model. They have a horizontal structure made up of some existing buildings that are part of the local culture; they base their competitive advantage on a close integration with the territory 
and on the exploitation of local resources. In addition, they are located in buildings of cultural and historical interest, far from mass tourism destinations, preserving the local identity and the original architecture. These structures are specifically appropriate for the new and original requirements of the tourism sector: by staying in these alberghi diffusi tourists can become an active part of the host community. The interviews showed that our case studies can positively meet the requirements of sustainability.

In order to protect and enhance the local setting, historic buildings were restored in the traditional architectural style, using reclaimed building materials (environmental efficiency); in these hotels generous use is made of local food and wine, they promote nature, artistic and food trails, allowing tourists to actively participate in the initiatives publicized by tourism associations (social efficiency). At the same time, the alberghi diffusi contribute to the development of the villages they are in, boosting their products, history and traditions: after the positive experience of their stay in the villages, tourists will keep buying the typical products they found there during their vacation, bringing competitive advantage to the territorial economy (economic efficiency).

Nevertheless, alberghi diffusi have often failed to exploit the potential offered by the local tourist resources and the increasing numbers of socially responsible tourists. The cause of this situation may reside in: a) existing regulations are inadequate to deal with a proper development of local and national tourism, b) the government has a poor record of taking action in favor of efficient and effective management of tourist flows, c) the government lacks the initiative to encourage the development of tourism in outlying areas.

Therefore, it is the decision makers' responsibility to promote actions aimed at the development of the territory. They also have the responsibility to encourage the development of both local and national tourism systems, to increase the competitiveness of Italian tourist destinations. This is not easy to achieve, because it requires huge investments of human and economic resources and the involvement of the public sector, and that would be difficult for small businesses like alberghi diffusi.

In accordance with Weaver's theory $(2000 ; 2010)$, the ability of a tourist destination to face competitors, i.e. its competitiveness, is based on the degree of sustainability of its tourist progress.

The position in the related matrix is due to both the value of the tourist intensity (number of tourists arriving and number of overnights) and of regulation level. A satisfactory level of sustainability can be achieved when two specific conditions are well balanced: tourist intensity (the percentage of tourists and dwellers, the quantity of workers, the number of accommodation and the average period of stays) and regulation (laws on tourism, on environment exploitation and its protection, respect for dwellers' needs and protective measures for the local cultural legacy).

The position of the albergo diffuso within the Weaver matrix needs to be analyzed from both a static and a dynamic perspective. Statically, our analysis shows that the alberghi diffusi (AD2) might place (taking into account the related differences) in the DAT quadrant (Fig. 2).

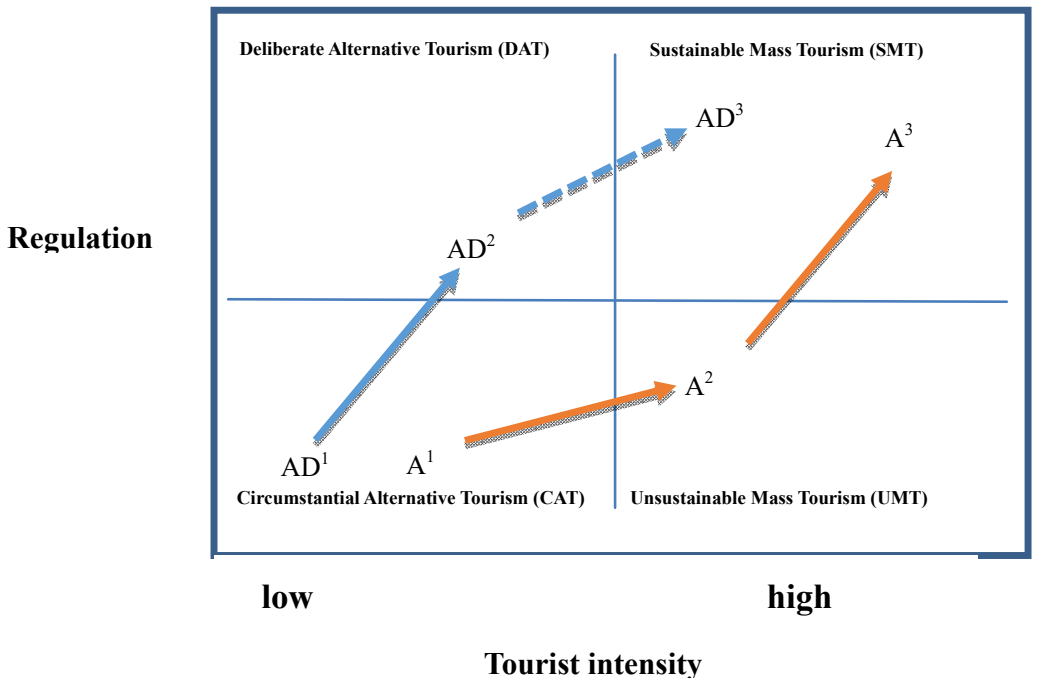

Figure 2. Alberghi Diffusi and rural tourism businesses (agritourism) within Weaver model 
In this respect, the examination of the questionnaire's responses obtained by entrepreneurs of alberghi diffusi, has emphasized the lack of local regulation and the following significant issues: a) insufficient coordination among authorities, such as Government, regions and association, 2) high level of bureaucracy that causes impasse and discourages the development of new poles, 3) vacancy of a governing authority to coordinate the tourism business, 4) heavy taxation hindering progress and competitiveness, 5) omission of a solid database of the tourism sector, 6) difficulty and long waiting to get tourist visas to emerging countries.

Therefore, the matter of the economic sustainability of these early-stage and high risk startup companies is of key importance and regulation is becoming more and more pressing and imperative. Furthermore, regulation is fundamental for alberghi diffusi under analysis, especially when its high level is not only achieved thanks to law prescriptions, but to ad-hoc policies issued by local authorities aiming at protecting the ecosystem, respecting dwellers and preserving the value of the territory as far as historical and architectural sites are concerned. All the same, if we place the alberghi diffusi in the Weaver matrix inside the DAT quadrant, we will observe that tourist intensity counts about as much as the variable regulation, in particular considering the sizeable tourist flows.

From a dynamical point of view, we can see that a progress would be advisable, moving towards Sustainable Mass Tourist, that is to say a real development founded on a precise set of laws and regulations for the management of tourist business: legislation to support this kind of hospitality is not exhaustive.

From a dynamic perspective, the albergo diffuso is placed in the CAT (AD1) quadrant. Only in the long term and thanks to the increase of tourist flows and regulations, it is able to reach the DAT (AD2) quadrant.

The position of the albergo diffuso within the Weaver matrix is relevant if compared to other types of tourist businesses, such as agritourism. Agritourism places itself in the SMT quadrant and represents a valid example for the albergo diffuso to aspire to over time.

Compared to the albergo diffuso model, agritourism has established itself as a sustainable hospitality model in the international tourism scenario for long time. Despite its evolution over time (from A1 to A3), it is placed in the SMT quadrant.

This is not only due to the increase of the number of tourists attracted by country life, but also to a greater attention of tourism legislation towards the environment safeguard.

In particular, tourist legislation has addressed the following issues: a)recovery of the rural architectural heritage, both modern such as country houses, and historical such as villas, towers, dovecotes, farms, etc., b)recovery of the landscape features of rural environment, such as farmyards, courtyards, rural trails leading to farms, walls, bushes, trees marking land borders, fences and historical gates, mills, etc., c)conservation of traditional food farming produce, d) cuisine based on traditional local recipes, e) whether required and possible, greater involvement of guests in the agrarian activities and in the farm's life, f) sale of products, if possible on-line, so as to facilitate those who do not travel by car, e.g by bycicle, g) creation of educational farms, but also summer camps with the possibility of overnight accommodation for children and teenagers, $h$ ) greater attention to the recovery of the territory's heritage: workshops on typical culinary and handmade activities, i) organization of guided tours (possibly on foot, by bicycle, or by horse) to museums, villas, rural villages, etc. Consequently, along the lines of the agritourism, the albergo diffuso might place itself in the SMT (AD3) quadrant, provided that, along with the increase of tourist flows, the legislative system adopts some measures aimed at supporting the sustainability of the tourist destination.

\section{Conclusion and Limits}

Does the model of "albergo diffuso" satisfy the requirement for a social, economic and environmental sustainability?

This paper aims to contribute to recent studies on the topic of alberghi diffusi, and tries to suggest some ways for tourism entrepreneurs and policy makers to improve their performance. The article addresses a very recent issue, for which there is yet no official quantitative measurement; so the discussion provides an opportunity to indicate how innovation would be significant in gaining a competitive advantage in the tourism sector, starting with the improvement of the regional regulations.

The alberghi diffusi can be considered a valid and sustainable hospitality business alternative to traditional Italian hotels. Their originality lies in their structure and means of service delivery, the emphasis on authentic experiences and the involvement of all its participants. In fact, they are not merely 'scattered' hotel accommodation with historical, cultural and artistic add-ons, but a programme aimed at promoting the history and culture of an area that can have a great effect on competitiveness through the development of the local economy, as has been demonstrated by certain examples of excellence. It can also be seen from the study that the 
albergo diffuso model assumes a) respect for and protection of the environment, especially of the ecosystem and biodiversity - the structures and tourist activities have minimum environmental impact; b) respect for and protection of the traditional culture of the local population; c) the tourist-oriented activities are shared by the local population; d) they also share in the social and economic benefits derived from tourism.

Within historic villages, tourism cannot become a mass phenomenon. However, it can play an important role in propagating local and regional interests in a new context that relies on the small tourist business in its role of a driving force for a healthier and more sustainable development of more territories and more and more local communities. From the legal point of view, clear and consistent rules in the field of alberghi diffusi are still lacking. In regions with a higher concentration of these, there is no proper regulation.

Moreover, the Institutions should make a major effort to organize, coordinate and promote a territory tourist offer, in order to make the Italian rural areas more attractive and competitive within the international tourism scenario.

Investments in promotional activities should be focused on those European countries which show strong differences in terms of per capita income and that, for this reason, can considerably influence the size of tourist flows (Norway, Sweden, Finland, Denmark, -France, _Switzerland and Austria). Naturally, investments in promotional activities should go hand in hand with the development of an effective and widespread tourist system, able to supply informative systems and qualified assistance for the reservations process, the planning of itineraries and the offer of organized tours. This would mean making less demanding and expensive the efforts that foreign tourists often have to face when they spend their holidays in Italy.

\subsection{Limits}

The paper discusses the implications of sustainability with particular regards to the "albergo diffuso". Therefore, it would be suitable to expand the analysis to additional models of tourist hospitality populating the international tourism scenario in order to identify their specific characteristics and their potential for competitive development. Future research will further clarify the relationships between the albergo diffuso model and the pursuit of sustainable goals by the businesses involved in developing the project. Another aspect that could be analysed in future would be how the local communities perceive the benefits offered by the alberghi diffusi; in other words, integrating stakeholder theory in this research, it would be interesting to find out if the local people feel themselves part of this project for improving the value of their territory. Finally, it would also be interesting to assess the actual value created by the alberghi diffusi, for themselves and for the territory, and propose empirical models for establishing lasting partnerships between the actors of both the tourism industry and the community.

\section{References}

Avram, M., \& Zarrilli, L. (2012). The Italian model of "Albergo Diffuso": A possible way to preserve the traditional heritage and to encourage the sustainable development of the Apuseni Nature Park. Journal of Tourism and Geo Sites, 9(1), 32-42.

Bieger, T. (1998). Reengineering destination marketing organizations - the case of Switzerland. The Tourist Review, 53(3), 4-17. https://doi.org/10.1108/eb058277

Baggio, R., Scott, N., \& Cooper, C. (2010). Improving tourism destination governance: A complexity science approach. Tourism Review, 65 (4), 51-60. http://dx.doi.org/10.1108/16605371011093863

Bramwell, B., \& Lane, B. (2011). Critical research on the governance of tourism and sustainability. Journal of Sustainable Tourism, 19(4/5), 411-421. http://dx.doi.org/10.1080/09669582.2011.580586

Buckley, R. (2012). Sustainable tourism: Research and reality. Annals of Tourism Research, 39 (2), 528-546. https://doi.org/10.1016/j.annals.2012.02.003

Buhalis, D. (2000). Marketing the competitive destination of the future. Tourism Management, 21. https://doi.org/10.1016/S0261-5177(99)00095-3

Chien-Min, C., Sheu Hua, C., \& Hong Tau, L. (2011). The destination competitiveness of Kinmen's tourism industry: exploring the interrelationships between tourist perceptions, service performance, customer satisfaction and sustainable tourism. Journal of Sustainable Tourism, 19(2), 247-264. http://dx.doi.org/10.1080/09669582.2010.517315

Choi, H. C., \& Sirakaya, E. (2006). Sustainability indicators for managing community tourism. Tourism Management, 27 (6), 1274-1289. https://doi.org/10.1016/j.tourman.2005.05.018

Coles, T., Fenclova, E., \& Dinan, C. (2013). Tourism and corporate social responsibility: A critical review and $\begin{array}{lllll}\text { research agenda. Tourism } & \text { Management }\end{array}$ 
https://doi.org/10.1016/j.tmp.2013.02.001

Confalonieri, M. (2011). A typical Italian phenomenon: The "albergo diffuso". Tourism Management, 32(3), 685-687. https://doi.org/10.1016/j.tourman.2010.05.022

De Montis, A., Ledda, A., Ganciu, A., Serra, V., \& De Montis, S. (2015). Recovery of rural centres and "albergo diffuso": A case study in Sardinia, Italy. Land Use Policy, 47, 12-28. http://dx.doi.org/10.1016/j.landusepol.2015.03.003

Dwyer, L., Edwards, D., Mistilis, N., Roman, C., \& Scott, N. (2009). Destination and enterprise management for a tourism future. Tourism Management, 30(1), 63-74. https://doi.org/10.1016/j.tourman.2008.04.002

Flagestad, A., \& Hope, C.A. (2001). Strategic Succes in Winter Sport Destination: A Sustainable Value Creation Perspective. Tourism Management, 22(5), 445-461. https://doi.org/10.1016/S0261-5177(01)00010-3

Fu Chen, C. \& DungChun, T. (2007). How destination image and evaluative factors affect behavioral intentions? Tourism Management, 28(4), 1115-1122. https://doi.org/10.1016/j.tourman.2006.07.007

Gossling, S., Hall, C. M., \& Weaver, D. B. (2009). Sustainable tourism futures. Perspectives on systems, restructuring and innovations. New York: Routledge.

Hall, C. M. (2010). Changing paradigms and global change: from sustainable to steady-state tourism. Tourism Recreation Research, 35, 131-143. http://dx.doi.org/10.1080/02508281.2010.11081629

Jamal, T., \& Stronza, A. (2009). Collaboration theory and tourism practice in protected areas: Stakeholders, structuring and sustainability. Journal of Sustainable Tourism, 17(2), 169-189. http://dx.doi.org/10.1080/09669580802495741

Monge, F., Cattaneo, D., \& Scilla, A. (2015). The widespread hotel: New model for business tourist. Journal of Investment and Management, 4, 69-76. https://dx.doi.org/10.11648/j.jim.s.2015040101.19

Nahapiet, J., \& Ghoshal, S. (1998). Social Capital, Intellectual Capital and the Organizational Advantage. Academy of Management Review, 23. https://doi.org/10.5465/AMR.1998.533225

Paniccia, P., Pechlaner, H., \& Valeri, M. (2010). The Importance of the Time of Experience in the Innovation of Tourism Business. The Sextantio "albergo diffuso". In K. Weiermair, F. Go, P. Keller, H. Pechlaner (Eds.), Entrepreneurship and Innovation in Tourism. Berlin: Erich Schmidt Verlag.

Paniccia, P., Silvestrelli, P., Montella, M., Rozera, C. \& Valeri, M. (2014). Innovare nell'ottica della sostenibilità. L'esempio dell' "albergo diffuso": un progetto di valorizzazione per il territorio. In M. Franch, M. Martini, (a cura di), Management per la sostenibilità dello sviluppo turistico e la competitività delle destinazioni. Il Mulino, Bologna.

Paniccia, P., \& Leoni, L. (2017). Co-evolution in tourism: the case of Albergo Diffuso. Current Issue in Tourism, 20(17), 1-28. http://dx.doi.org/10.1080/13683500.2017.1367763

Paniccia, P., Pechlaner, H., \& Valeri, M. (2010). The Importance of the Time of Experience in the Innovation of Tourism Business. The Sextantio "albergo diffuso". In K. Weiermair, F. Go, P. Keller, H. Pechlaner (Eds.), Entrepreneurship and Innovation in Tourism. Berlin: Erich Schmidt Verlag.

Ritchie, J. R. B., \& Crouch, G. I. (2000). The Competitive Destination: A Sustainable Perspective. Tourism Management, 21(SI), 1-7. https://doi.org/10.1079/9780851996646.0000

Ruhanen, L., Scott, N., Ritchie, B. \& Tkaczynski, A. (2010). Governance: A review and synthesis of the literature. Tourism Review, 65(4), 4-16. https://doi.org/10.1108/16605371011093836

Saarinen, J. (2006). Traditions of sustainability in tourism studies. Annals of Tourism Research, 33(4), 1121-1140. https://doi.org/10.1016/j.annals.2006.06.007

Sainaghi, R. (2006). From Contents to Processes: Versus a Dynamic Destination Management Model (DDMM). Tourism Management, 27(5), 1053-1063. https://doi.org/10.1016/j.tourman.2005.09.010

Schianetz, K., Kavanagh, L., \& Lockington, D. (2007). The Learning Tourism Destination: The potential of a learning organization approach for improving the sustainability of tourism destinations. Tourism Management, 28(6), 1485-1496. https://doi.org/10.1016/j.tourman.2007.01.012

Tani, M., \& Papaluca, O. (2015). Local Resources to Compete in the Global Business: The Case of Sextantio Hotels. Handbook of Research on Global Hospitality and Tourism Management, 119. http://dx.doi.org/10.4018/978-1-4666-8606-9.ch008 
Twining-Ward, L., \& Butler, R. (2002). Implementing STD on a small island: Development and use of sustainable tourism development indicators in Samoa. Journal of Sustainable Tourism, 10(5), 363-387. http://dx.doi.org/10.1080/09669580208667174

Valeri, M. (2015). Sustainability development and competitiveness of Rome as a tourist destination. Tourism and Hospitality Management, 21(2), 203-218.

Valeri, M., \& Fadlon, L. (2016). Sustainability in tourism: an originality and hospitality business in Italy. Tourismos, 11(1), 1-18.

Valeri, M., Pechlaner, H., \& Gon, M. (2016) (a cura di), Innovazione, sostenibilità e competitività. Teoria ed evidenze empiriche, Giappichelli editore, Torino.

Vallone, C., Orlandini, P., \& Cecchetti, R. (2013). Sustainability and innovation in tourism services: the Albergo Diffuso case study. Eurasian Journal of Social Sciences, 1(2), 21-34.

Volgger, M., \& Pechlaner, H. (2015). Governing networks in tourism: what have we achieved, what is still to be done and learned?. Tourism Review, 70(4), 298-312. http://dx.doi.org/10.1108/TR-04-2015-0013

Warnken, J. \& Buckley, R. (1998). Scientific quality of tourism environmental impact assessment. Journal of Applied Ecology, 35(1), 1-8. http://www.jstor.org/stable/2405182

Weaver, D. B. (2000). The Exploratory War-distorted Destination Life Cycle. International Journal of Tourism Research, 2(3),

151-161. https://doi.org/10.1002/(SICI)1522-1970(200005/06)2:3<151::AID-JTR196>3.0.CO;2-G

Weaver, D. B. (2010). Indigenous tourism stages and their implications for Sustainability. Journal of Sustainable Tourism, 18, 43-60. http://dx.doi.org/10.1080/09669580903072001

Weaver, D. B. (2012). Organic, incremental and induced paths to sustainable mass tourism convergence. Tourism Management, 33(5), 1030-1037. https://doi.org/10.1016/j.tourman.2011.08.011

Weaver, D. B. (2014). Asymmetrical dialectics of sustainable tourism: toward enlightened mass tourism. Journal of Travel Research, 53(2), 131-140. https://doi.org/10.1177/0047287513491335

Weaver, D. B. (2017). Sustainability and mass tourism: a contradiction in terms? In D. Harrison \& R. Sharpley (Eds.), Mass tourism in a small world. Cabi international, Uk.

World Commission on Environment and Development. (1987). Our common future - The Brundtland report. New York Oxford: University Press.

Yin, R. K. (2009). Case study research: Design and methods (3nd ed.). Thousand Oaks, Sage Publications, Calif.

Zografos, C., \& Oglethorpe, D. (2004). Multi-criteria analysis in ecotourism: Using goal programming to explore sustainable solutions. Current Issues in Tourism, 7(1), 20-43. http://dx.doi.org/10.1080/13683500408667971

\section{Copyrights}

Copyright for this article is retained by the author(s), with first publication rights granted to the journal.

This is an open-access article distributed under the terms and conditions of the Creative Commons Attribution license (http://creativecommons.org/licenses/by/4.0/). 